\section{DENTIST CAPTURES SOULS ON FILM} ADAPT (Aesthetic Dentistry and Professional Testing) and Director of Dental Education Ltd, has fulfilled a parallel ambition as portrait photographer.

This autumn Torelli in Kew has been holding an exhibition of some of Dr Stean's work, both studio and location portraits in black and white, including the image (pictured right) of actor/entertainer John Barrowman.

'I've always had a real interest in photography. It has assisted me in my career in dentistry and digital photography has been a real advantage for recording and documenting my dental work, said Dr Stean. 'However, for me the real creative pleasure entails using film and good equipment to capture that fleeting moment, the soul of the person if you will. No digital image can equal the thrill of making a real silver print of an interesting subject.'
Dr Howard Stean, restorative dentist, Chairman of

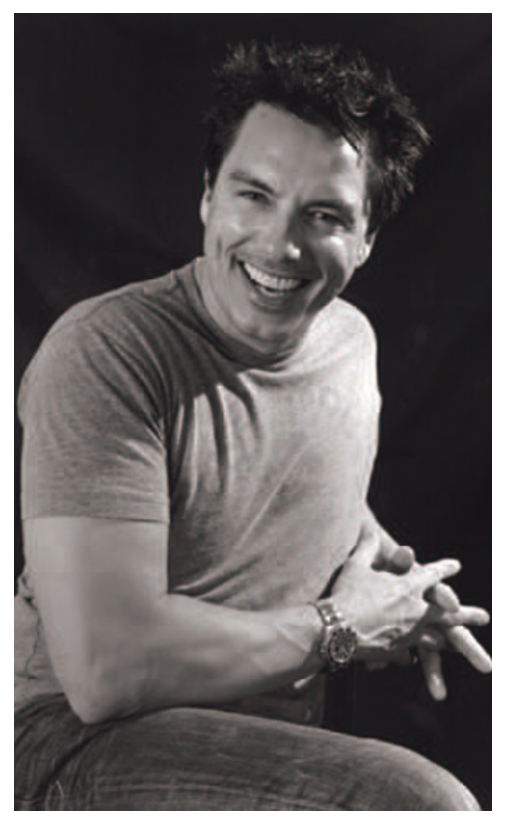

\section{BDA BULLETIN}

- The BDA is hosting a new training event designed to help dentists detect signs of oral pre-cancer and cancer. It is hoped the event will help save patients' lives and, by doing so, prevent dentists from being swept up in the growing wave of legal cases being brought against practitioners by patients whose symptoms have been missed. The one day course for the whole dental team will run for the first time on 25 November during Mouth Cancer Action Month 2011 at the BDA's London headquarters. http://www.bda.org/events/958training-essentialsoral-cancer-thedental-team's-responsibilityfriday25-november-2011london.aspx
- New figures published by the NHS Information Centre in October show a fall in dentists' average taxable income of 5.2\% in 2009/10 compared with 2008/09. The average taxable income for all self-employed primary care dentists in England and Wales in 2009/10 was £84,900, compared to $£ 89,600$ in $2008 / 09$, according to the report Dental earnings and expenses, England and Wales 2009/10. The figures represent a significant pay cut and reflect increases in practice expenses of $3.1 \%$ over the period, following an increase of $7.6 \%$ in expenses in the previous year.

- The BDA is pleased to see the publication of a World Health Organisation (WHO) report on the use of different materials in dental fillings. The report, Future use of materials for dental restorations, says that it may be prudent to consider a phasing-down, rather than a phasing-out, of the use of dental amalgam and calls for a multi-pronged strategy with short-, medium- and long-term elements. It also contends that the quality of alternatives to amalgam must be further improved for use in public dental care, arguing that a progressive move away from amalgam would be dependent on that quality improvement being achieved.

\section{CDS NEEDS TO PULL TOGETHER}

In her first address as the incoming BDA Community Dental Services (CDS) Group President, Dr Borghild Breistein said that salaried staff need to pull together in these challenging economic times.

Speaking at the CDS Group's Annual Conference in Belfast from 13-14 October, Dr Breistein said she understood the anxieties felt by CDS staff about possible cuts and redundancies, but said there was hope that the services that are the most efficient and effective will continue to be supported.

The conference focused on supporting members of the salaried dental services to ensure they are providing care that is evidence-based and of the highestquality, as well as offering practical tips on managing this highly challenging patient group, which includes those from the most deprived communities and the elderly.

Practical sessions offered tips on dealing with dentally phobic children, caries control in vulnerable patients and periodontal management in unmanageable situations.

You can listen again to short audio highlights from the key speakers' presentations at www. bda.org/dentists/representation/ salaried-primary-care-dentists/ cds-group.
DIARY

\section{DECEMBER}

FGDP(UK) Whitening Study Day

and Workshop

Date: 2-3 December 2012

Venue: Glasgow Science Centre

www.fgdp-scotland.org

BACD London Study Club

'Direct Resin Artistry'

Date: 5 December 2012

Venue: BDA, London

Telephone: 02076124166

Email:suzy@bacd.com

\section{2}

7th annual Young Dentist Conference Date: 4 February 2012

Venue: Shaw Theatre,

Novotel St Pancras London

Telephone: 02073992914

www.dentalprotection.org/ydc

Dental Hypnosis 1: Technical

Foundations and Dental Hypnosis

2: Applied Clinical Skills

Date: 22-23 February 2012

Location: Central London

Telephone: 02073851166

Email:info@ihmdp.org

BDA Events: Setting up in practice: how to succeed in challenging times Date: 9 March 2012

Location: Leeds

Telephone: 02075634590

(quote 'SUIP1' to book a second

place half price)

British Dental Conference

and Exhibition 2012

Date: 26-28 April 2012

Venue: Manchester Central

Convention Complex

www.bda.org/conference

Excellence in Dentistry

2012 Conference

Date: 26-29 April 2012

Location: Istanbul

www.excellence-in-dentistry.org

Dental Sedation Teachers Group

Annual Symposium 2012

Date: 22 May 2012

Venue: St. Paul's Mecure Hotel,

Sheffield

Email: sheelah.harrison@sheffield.ac.uk www.dstg.co.uk 